prospective study of the efficacy of HCR-20, PCL-R and psychiatric symptomology. J Consult Clin Psychol 2003; 71: 443-51.

6 Grevatt M, Thomas-Peter B, Hughes G. Violence, mental disorder and risk assessment: can structured clinical assessments predict the short-term risk of inpatient violence? J Forens Psychiatr Psychol 2004; 15: 278-92.

7 Doyle $M$, Dolan $M$. Predicting community violence from patients discharged from mental health services. Br J Psychiatry 2006; 189: 520-6.

8 Gray NS, Snowden RJ, MacCulloch S, Phillips H, Taylor J, Macculloch MJ. Relative efficacy of criminological, clinical and personality measures of future risk of offending in mentally disordered offenders: a comparative study of HCR-20, PCL:SV and OGRS. J Consult Clin Psychol 2004; 72: 523-30.

9 World Health Organization. The ICD-10 Classification of Mental and Behavioural Disorders. WHO, 1992.

10 Douglas KS, Ogloff JRP, Nicholls TL, Grant I. Assessing risk for violence among psychiatric patients: the HCR-20 violence risk assessment scheme and the psychopathy checklist: screening version. J Consult Clin Psychol 1999; 67: 917-30
11 Maden A, Scott, F, Burnett R, Lewis GH, Skapinakis P. Offending in psychiatric patients after discharge from medium secure units: prospective national cohort study. BMJ 2004; 328: 1534.

12 Green DM, Swets JA. Signal Detection Theory and Psychophysics. Wiley, 1966.

13 Rice ME, Harris GT. Comparing effect sizes in follow-up studies: ROC area Cohen's $d$ and r. Law Hum Behav 2005; 29: 615-20.

14 Snowden RJ, Gray NS, Taylor J, MacCulloch MJ. Actuarial prediction of violent recidivism in mentally disordered offenders. Psychol Med 2007; 37: 1539-49.

15 Douglas KS, Yoemans M, Boer DP. Comparative validity analysis of multiple measures of violence risk in a sample of criminal offenders. Crim Justice Behav 2005; 32: 479-510.

16 De Vogel V, de Ruiter C. Differences between clinicians and researchers in assessing risk of violence in forensic psychiatric patients. J Forens Psychiatr Psychol 2004; 15: 145-64.

\title{
Why psychiatry still needs psychoanalysis
}

\section{Jeremy Holmes}

Because illness-bearers, our patients, come to us not just with diagnoses but with their dreams and character. In dreams lie cherished fears and desires. Character is the precipitate of our material and social being - genes, developmental experiences, choices, relationship patterns, strengths and weaknesses. We are largely unaware of these deep structures that constitute the self. Psychoanalysis provides a language for describing the development of character and for reading dreams. The psychiatrist versed in that language can converse with their patients about how they came to be who they are, and how best to cope with the adversities of mental illness. 